\title{
Tennessee Vans: \\ A User-Based and Financially- Sustainable Approach to Develop Community Mobility Resources
}

\author{
Theodore J. Newsom and Danielle F. Meyers \\ University of Tennessee
}

\begin{abstract}
Although substantial resources have been devoted to the provision of the transportation infrastructure needed to support the movement of people, there still exist "mobility gaps," especially among transportation disadvantaged groups of persons. An approach to fill these community mobility gaps is based on the experimental and evolving development and operations of Tennessee Vans over the past 20 years. The Tennessee Vans fleet has grown to 845 vehicles assigned to more than $300 \mathrm{com}$ munity groups and organizations as part of its vehicle lease and purchase programs. Program participants include community and economic development agencies, faith-based organizations, commuter vanpools, youth-based organizations, workforce development groups, and public/private transit agencies. A financial analysis indicated that in model year 2007 Tennessee Vans had achieved its major goal of becoming financially self-sufficient through its revenue generation capabilities and recycling of program revenue to procure additional vehicles and finance program operations.
\end{abstract}




\section{Introduction}

In recent years, much has been written about human mobility and its importance for community, economic, and human growth and development for all groups of people (Garrison and Ward 2000; Urry 2007; Jones 2008; Staley and Moore 2009). These discussions point out that, although substantial resources have been devoted to the provision of the transportation infrastructure needed to support the movement of people, there still exist what are termed "mobility gaps." These mobility gaps occur when the transportation needs of individuals or groups are not being met by current transportation service options. The occurrence of mobility gaps is especially apparent among transportation disadvantaged groups, including persons with disabilities, youth, older adults, and low income workers.

For decades, transportation professionals have designed and developed alternative approaches to address the mobility needs (including mobility gaps) that occur in all communities. In addition to road development approaches that support the use of highway vehicles, various approaches have been used to move people from place to place (Research and Training Center on Disability in Rural Communities 2007). These include public transportation models (fixed-route, demand responsive, deviated fixed-route services), agency-focused models (specialized transit services), cooperative models (coordinated services, brokerages, consolidated services), volunteer and voucher models (volunteer systems, community inclusion drivers, vouchers), and public-private partnerships (taxi coupon models, personal vehicle ownership). The mobility services offered through these and other transportation approaches, such as commuter ridesharing and transportation demand management services, can be found in most communities. Yet there still remains a lack of infrastructure and services to address or fill the mobility gaps that continue to occur. Clearly, there is an ongoing need to design and develop additional mobility resources to address persistent community transportation issues.

The purpose of this paper is to present an approach for the development of community mobility resources. This approach is based on the experimental and evolving development and operations of Tennessee Vans over the past 20 years. Tennessee Vans is a statewide transportation service that provides vehicles for lease and/ or purchase to commuter groups, employers, public agencies, and private nonprofit community organizations. In exchange for access to vehicles and affordable financing provided by Tennessee Vans, the program participants agree to provide safe and reliable transportation services to meet identified mobility needs. 
The characteristics that distinguish Tennessee Vans from other approaches include its flexibility to meet diverse mobility needs and fill mobility gaps, a primary emphasis on user-based service design, serving the basic role as a mobility resource provider, and a central focus on financial self-sufficiency and program sustainability. Tennessee Vans is a human mobility system designed to address the changing nature of mobility needs and the growing demands for transportation resources among diverse population groups throughout Tennessee (Newsom 1999; Wegmann and Newsom 2002). Mobility gaps addressed by Tennessee Vans typically occur when existing urban and rural transit providers are unable to provide access to desired destinations (e.g., work sites, medical facilities, retail stores) when and where they are needed by program participants. Transit service routes and schedules either are inconvenient or the services do not exist at all. Unlike traditional paratransit services with paid drivers, centralized dispatch, etc., Tennessee Vans services are user-centric. The basic premise of allowing program participants to design the mobility services that directly meet their needs is a key to success in terms of assuring accessibility to desired services and activities. Tennessee Vans serves primarily as a mobility resource provider and is available to assist program participants with the implementation of their service designs by providing vehicles and associated services. In addition, a major goal of Tennessee Vans is to become financially self-sufficient and maintain the viability of program services. The financial strategy used for revenue generation and recycling of program funds facilitates program sustainability and cost effectiveness.

The remainder of this paper includes a presentation and discussion about the major features of the Tennessee Vans program, including its basic program services, the involvement of program participants, its revenue generation and financial selfsufficiency strategy, and future plans for program sustainability.

\section{Basic Program Services}

The Tennessee Vans program was initiated on February 1, 1990. Its mission is to expand mobility options for persons throughout Tennessee, thereby encouraging community, economic, and human growth and development. The Tennessee Vans program is operated by the University of Tennessee Center for Transportation Research and provides vehicles for lease and/or purchase by commuter groups, employers, private agencies, and public and non-profit community organizations. Tennessee Vans uses grant funds provided by federal, state, and local sources to purchase vehicles for use by program participants. The vehicle costs and operating 
expenses for Tennessee Vans are recovered from program participants through fees charged for the lease or purchase of vehicles. These generated funds are in turn used to purchase vehicles to replace older vehicles or add more vehicles to the fleet.

Program participants are identified through contacts with employers, business and community organizations, faith-based organizations, transportation agencies, public promotional activities, and by word of mouth. Interested parties complete and submit a program application for approval to participate in the program and to receive a vehicle assignment. Qualified program participants can lease and/or purchase Tennessee Vans vehicles. Three basic service programs are available: the Employee Vanpool Lease Program, the Agency Vehicle Lease Program, and the Agency Vehicle Purchase Program.

The Employee Vanpool Lease Program provides vehicles, insurance, maintenance, and fleet management assistance to commuter groups who want to travel to and from work in a vanpool. Minivans and 15-passenger vans are provided to groups of commuters who wish to ride together and share the monthly costs of operating the vanpool. The monthly fee covers the vehicle costs, fleet management expenses, maintenance, gasoline, and insurance. Insurance coverage is arranged through Tennessee Vans and paid for by each commuter group. The insurance includes $\$ 1$ million liability coverage and $\$ 5,000$ medical coverage, and physical damage coverage is self-insured. A member of the commuter group volunteers to drive the van, collect monthly rider fares, and keep the vehicle properly serviced. The typical vanpool monthly lease fee for a current model 15 -passenger van traveling 70 miles round trip daily is $\$ 780$. Each member of the group pays a portion of the monthly fee (e.g., $\$ 65$ each for a group of 12 paying passengers).

The Agency Vehicle Lease Program provides the opportunity for public and private organizations to provide transportation through an affordable vehicle lease plan. Transportation services include transporting persons to and from work, job training sites, work-trip related events, and other activities that facilitate the mobility and meet the travel needs of persons served by the organization. Qualified agencies pay monthly vehicle lease fees on a fixed cost plus mileage basis. The agencies provide their own insurance at program-specific coverage levels ( $\$ 1$ million liability, $\$ 1$ million uninsured motorist, comprehensive and collision with $\$ 500$ deductibles). The lease costs include the cost of the vehicle, vehicle maintenance, and fleet management expenses. A typical agency monthly lease fee for a current model 15-passenger van is $\$ 450$ fixed cost per month plus $\$ .10$ per mile. 
The Agency Vehicle Purchase Program provides the opportunity for program participants to purchase vehicles for transportation purposes through an affordable financing plan. Participants include public and private non-profit organizations that currently provide or would like to provide transportation services. Vans are assigned to participating organizations through simple purchase contracts. The participating organization agrees to pay monthly fees until the vehicle contract is paid in full. Upon payment of the vehicle contract cost, the vehicle title is fully transferred to the participating organization. Under the vehicle purchase program, the program participant provides the vehicle insurance (same coverage as agency lease program), maintenance services, and qualified drivers. The typical agency vehicle purchase contract cost for a current model 15-passenger van is $\$ 25,000$. The contract cost is amortized over 72 months with monthly payments of approximately $\$ 348$.

Since its inception in 1990 through the 2009 vehicle model year, the Tennessee Vans fleet has grown to 845 vehicles assigned to more than 300 groups and organizations located throughout Tennessee (Figure 1). The total number of vehicles grew rapidly during the 1990 s and through 2002, when the economy was relatively strong, vehicle demand was high, and financial resources were available to program participants. From 2003 until 2009, the program growth was slowed due to the sluggish economy and recent financial crisis. During this period, the number of retired vehicles (vehicles sold at auction and paid-up purchase contract vehicles) outpaced the number of new vehicles added to the fleet. The number of vehicles in service decreased, but since 2006 has stabilized at approximately 200 vehicles per year. Program growth for Tennessee Vans follows closely the ups and downs of the economy and associated fluctuations in vehicle market demand.

Figure 2 shows the distribution of vans across the purchase, agency lease, and vanpool service program categories. As shown, most of the vehicles were assigned to the vehicle purchase program (60\%). Participants favor the purchase program since they will acquire a real asset when the vehicle contract cost provisions are fulfilled and the vehicle title is transmitted to them. The employee vanpool lease program accounts for 22 percent of the vehicles. Tennessee Vans offers vanpoolers who are not interested in becoming owner operators the option to lease a van on a month to month basis. Eighteen percent (18\%) of the vehicles were assigned to participants in the agency lease program. This leasing option provides services for agencies that prefer not to commit to a long-term purchase contract or are unable to purchase a vehicle due to financial constraints or grant funding restrictions. 


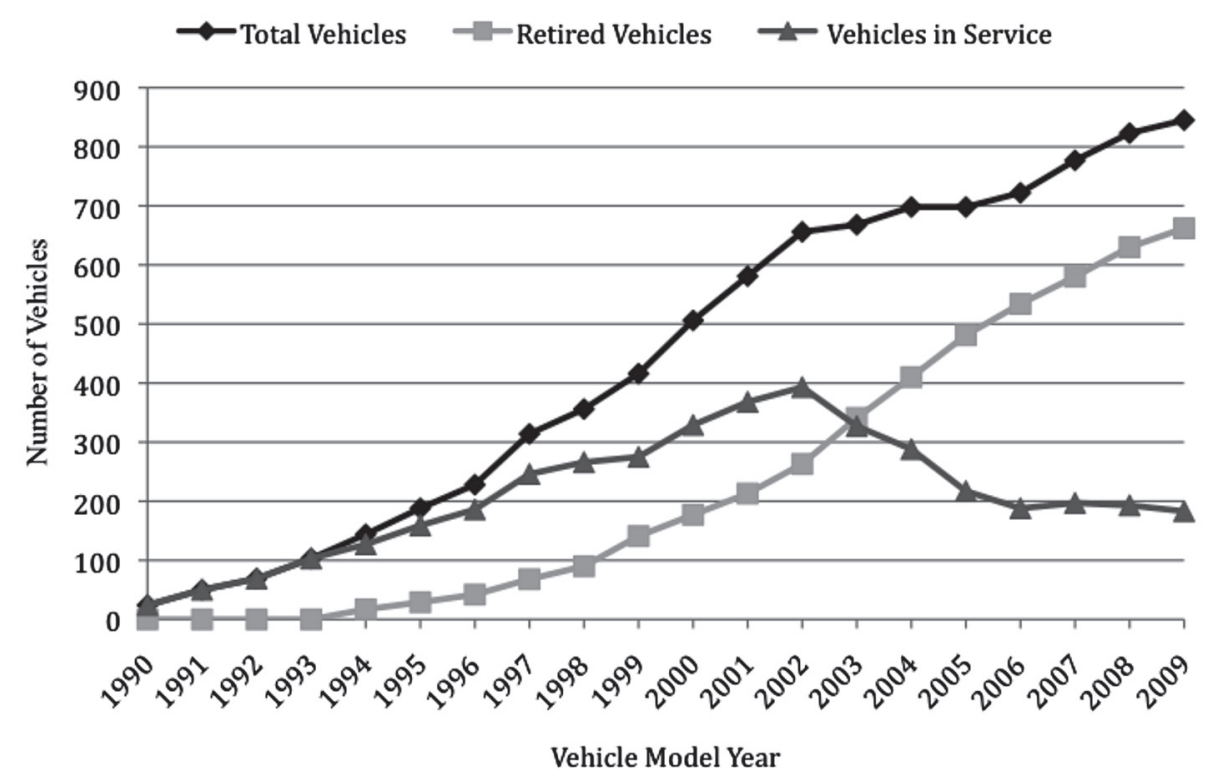

Figure 1. Number of Tennessee Vans.



Figure 2. Vehicle distribution by program category.

Figure 3 shows the distribution of the total vehicles across program vehicle fleet categories.

The categories reflect the status of program vehicles and include vehicles that have been sold at auction, vehicles that have been paid in full and titles sent to program participants, and vehicles that remain in current operating service. Of the total number of 845 vehicles in the fleet, 22 percent of the vehicles are in current operating service. Of the remaining vehicles, 40 percent have been sold at auction and 
38 percent have been paid in full by participants in the vehicle purchase program. The amount of revenue received was $\$ 8,290,082$ for the vehicles sold at auction and $\$ 7,117,340$ for the vehicles with paid-up purchase contracts. The vehicles in current operating service generate approximately $\$ 850,000$ in revenue per year. The overall program status for vehicles changes from year to year depending on the number of leased vehicles replaced and sold at auction, purchase contracts fulfilled, and new vehicles ordered and placed in service.

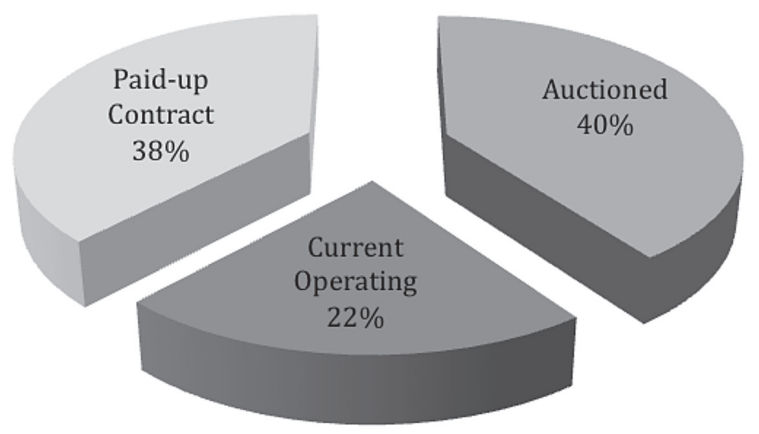

Figure 3. Vehicle distribution by fleet category.

\section{Vehicle Fleet}

Vehicles for Tennessee Vans program participants are procured through the University of Tennessee competitive bid process. The primary vehicles used by program participants are the 15-passenger van and the minivan. Table 1 shows the number of vehicles and various vehicle models that have been procured and assigned to program participants from model year 1990 through model year 2009. The vehicles include Ford, Dodge, Chevrolet, and GMC models. Most of the vehicles (69\%) used by program participants are 15-passenger vans. Minivans comprise 23 percent of the fleet. Eight percent of the fleet includes alternative vehicles that were procured and used to address specific vehicle safety and child care transportation issues.

The vehicle fleet includes models other than the traditional 15-passenger van and minivan. The Ford 12-passenger van and 14-passenger van (with a center aisle) and the 10-passenger Dodge Sprinter included technical specifications (electronic stability control technology and three-point seat belt systems in all seating positions) to address safety issues related to vehicle rollover problems. The Multi-Function School Activity Bus (MFSAB) was added to meet new state childcare transportation regulations requiring child care agencies to transport children in school- 
bus-type vehicles. Working with the various user groups to procure appropriate vehicle technology and develop effective safety information programs to address vehicle safety problems and issues has been an ongoing concern of Tennessee Vans (Newsom and Meyers 2003; Newsom, Meyers, and Gilpin 2005; Wegmann and Noltenius 2008).

Table 1. Tennessee Vans Fleet Composition (MY 1990-2009)

\begin{tabular}{|c|c|c|c|}
\hline Vehicle Model Type & Manufacturer & Total \# & $\%$ of Fleet \\
\hline \multirow[t]{3}{*}{ 15-Passenger Van } & Ford & 188 & \\
\hline & Dodge & 386 & \\
\hline & Chevrolet & 8 & \\
\hline Subtotal & & 582 & $69 \%$ \\
\hline \multirow[t]{4}{*}{ Minivan } & Ford & 23 & \\
\hline & Dodge & 12 & \\
\hline & Chevrolet & 122 & \\
\hline & GMC & 38 & \\
\hline Subtotal & & 195 & $23 \%$ \\
\hline \multirow[t]{4}{*}{ Alternative Vehicle } & Ford (12-passenger) & 5 & \\
\hline & Ford (14-passenger) & 47 & \\
\hline & Dodge Sprinter & 3 & \\
\hline & MFSAB (childcare bus) & 13 & \\
\hline Subtotal & & 68 & $8 \%$ \\
\hline TOTAL & & 845 & $100 \%$ \\
\hline
\end{tabular}

The physical locations of the vehicles throughout the state of Tennessee are shown in Figure 4. The majority of the vehicles are located in and around large urban population centers, such as Shelby, Knox, and Davidson counties. The remaining vehicles are spread throughout the small urban and rural counties. At least one vehicle is located in more than half of the 95 counties in Tennessee. The map depicts where vehicles are physically located by county; however, the vehicle service areas are not limited to county boundaries and more often than not the vehicle service areas span adjacent counties. 


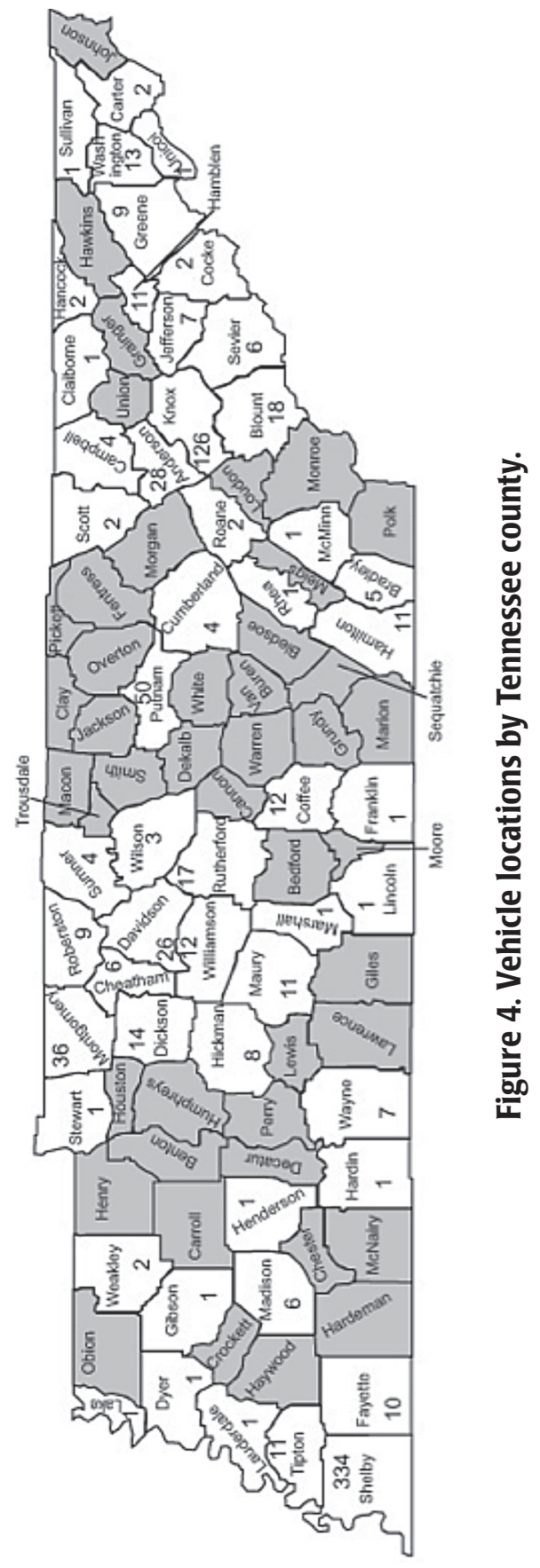


Program research studies (Wegmann 2001; Wegmann and Newsom 2002) indicate that the average vehicle traveled about 1,102 vehicle miles per month. Approximately 4,308 persons per month were transported, and about 181,667 monthly trips were made (about 2.1 million trips annually). During the time period for these studies, the annual trips for rural transit operators in Tennessee was 1.1 million, 2.8 million for fixed route transit in eight small cities, and 22.6 million for the four large cities. These studies also indicated that the environmental benefits generated by Tennessee Vans include a reduction in air pollution by $44,453,000$ grams/day for HC; 418,649,000 grams/day for CO; and 29,330,000 grams/day for NOX; and a reduction in fuel consumption by 1.4 million gallons annually.

\section{Program Participants}

The Tennessee Vans program provides vehicles and services to a diversity of participant groups, including community and economic development agencies, faith-based organizations, commuter vanpools, youth-based organizations, workforce development groups, and public/private transit providers. Each category of participants contains a variety of program users. For example, health care facilities, residential group homes, women's shelters, and refugee service programs are included among the participants in the community and economic development category. The work force development category includes participants from educational facilities, supported employment programs, and job training programs. Other examples of the array of participating organizations within each category are shown in Table 2.

The percent of vehicles assigned to each participant group is shown in Figure 5. Participant groups that account for approximately 71 percent of the vehicle fleet include the community and economic development group (29\%), faith-based organizations (22\%), and commuter vanpools (20\%). Youth-based organizations (14\%), workforce development programs (8\%), and transit providers (7\%) account for the remainder of the vehicle fleet.

These participant groups use the Tennessee Vans vehicles for a variety of mobility needs. For example, community and economic development organizations transport program staff and residents to community-based training activities and events. Some organizations provide vehicles to residential group homes to meet mobility needs in support of independent living arrangements. Public transit providers in urban and rural areas transport clients to jobs, employment training, medical 
Table 2. Tennessee Vans Participant Categories

\begin{tabular}{|l|l|}
\hline Community and Economic Development & Work Force Development \\
\hline Health Care Facilities & Educational Facilities \\
\hline Housing Authorities & Private Industry Councils \\
\hline Environmental Groups & Supported Employment \\
\hline Community Development & Job Training Placement \\
\hline City and County Agencies & Employers \\
\hline Residential Group Homes & Work Release Programs \\
\hline Drug Elimination Programs & Commuter Vanpools \\
\hline Women's Shelters & Employee Groups \\
\hline Refugee Service Programs & Employer Sponsored Groups \\
\hline Senior Citizen Centers & Ridesharing Agencies \\
\hline Public/Private Transit Providers & Faith-Based Organizations \\
\hline Rural Transit Agencies & Social Services \\
\hline Urban Transit Agencies & Community Outreach \\
\hline Transportation Businesses & \\
\hline Youth-Based & \\
\hline Day Care Centers & \\
\hline Youth Service Programs & \\
\hline
\end{tabular}

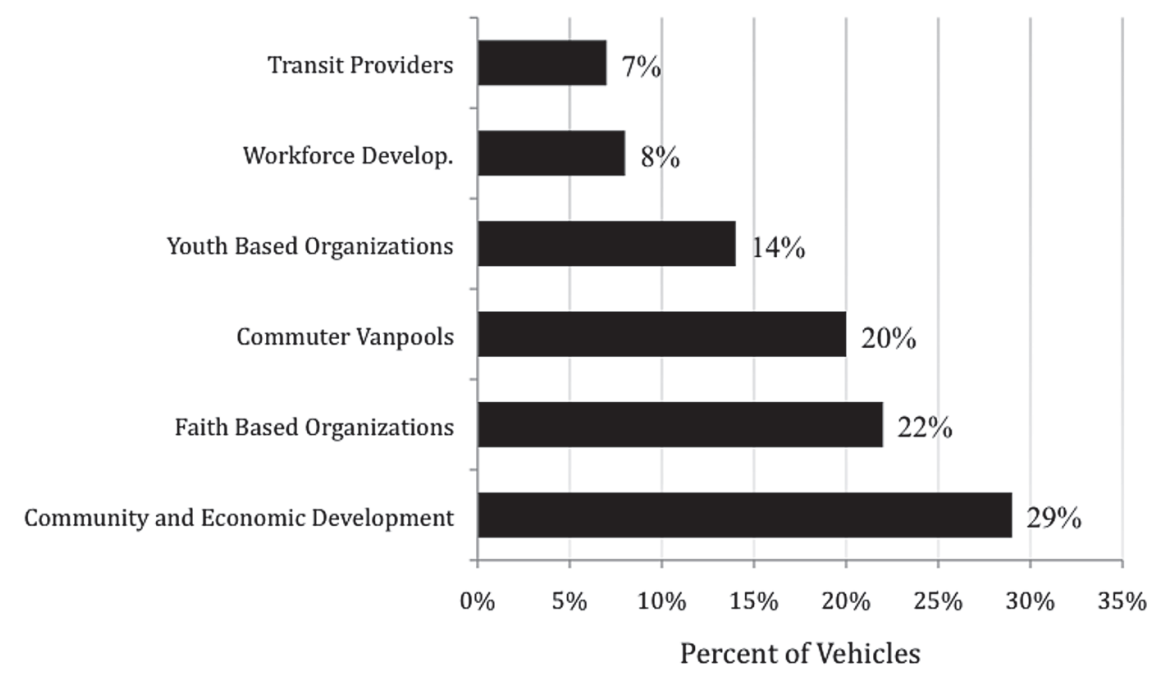

Figure 5. Percent of vehicles by participant group. 
appointments, and recreational activities. Work force development organizations use vans to transport clients from community homes to jobs and training facilities. They also transport clients from central training facilities to job interviews and other work-related events and activities. Youth groups use the vehicles to transport their clients to and from activities such as computer training at their central facilities, as well as to community-based activities and for field trips. Faith-based organizations use vans to support their community-based ministries and services. The vehicles are used to meet the mobility needs of youth ministries, after-school service programs, and senior services. Vehicles also are used to transport clients to and from day care centers and other events in the community. The vehicles also are used for commuter vanpooling. Several employee vanpool groups lease vans from the program to travel to and from work and share the travel costs. Employers also have leased vehicles to recruit, hire, and transport employees to worksites.

Periodic surveys, interviews, and focus groups with program participants have been conducted to obtain qualitative information regarding user perceptions and reactions to the Tennessee Vans program (Wegmann and Newsom 2002; Newsom and Meyers 2003; Wegmann and Noltenius 2008). Participant responses during these studies indicated that many of the organizations (34.5\%) could not maintain their existing programs without access to a Tennessee Vans vehicle. When asked about the importance of Tennessee Vans to their organizations, typical responses would include, "Without Tennessee Vans we would not be able to do what we're doing. The vans are allowing us to expand our outreach program." and "Our program would come to a screeching halt without the vans. Without the vans, services could not be offered, so they are essential." Participants (23.8\%) also stated that some of their clients would be left without mobility and could not participate in the programs. A small number of participants (13.1\%) stated that their clients could rely on public transit or walking, and some participants (21.4\%) stated that clients would have to rely on private vehicles, parents, or carpooling. Tennessee Vans vehicles are operated by many organizations that provide essential mobility to their clients. Closure and curtailment of services would negatively impact all program participants.

While some organizations use Tennessee Vans vehicles to supplement their fleets purchased from other sources, many had attempted to purchase a vehicle from a private dealership with little success. In most cases, the private sector would not provide the financial flexibility or extend the credit required for the organization to secure a van. Also, about a fourth of the organizations attempted to acquire a 
vehicle as part of public capital grant programs, but without success, since these grants are very competitive and the agencies did not meet the applicant qualifications. Almost half of the organizations reported that a Tennessee Vans vehicle replaced an older vehicle. These organizations benefited from acquiring a newer, safer, and more reliable vehicle.

As part of these research studies, program participants were asked about the resources used to pay for the Tennessee Vans vehicles. Program participants reported that these resources include passenger fares (6.1\%), program revenue (19.5\%), daycare or tuition fees (9.8\%), social service grants and state vouchers (23.2\%), and donations (41.4\%). Participants also indicated that the Tennessee Vans vehicles were used because of the attractive payment plan and reasonable rates (61.0\%) and that no down payment was required (35.0\%). It is clear that these organizations value the simplicity and financial flexibility provided by Tennessee Vans because many are not financially able to use conventional credit to lease or purchase a vehicle.

\section{Revenue Generation and Financial Self-Sufficiency}

The basic framework that guides the Tennessee Vans financial strategy is depicted in Figure 6. This financial strategy for maintaining the viability and longevity of the program is the defining characteristic that sets Tennessee Vans apart from other community mobility resource development programs. The initial seed grants were provided by local, state, and federal governments with the stipulation and expectation that Tennessee Vans will maximize vehicle and operating cost recovery. Tennessee Vans strives to constrain operating expenses, minimize financial losses, and maximize revenue generation. Revenues received from program participants are used to purchase replacement vehicles in the lease program and to procure additional vehicles for the purchase program. The use of these vehicles generates revenue that, in turn, is used to pay expenses and procure additional vehicles for future use. This recycling of revenue contributes to the growth of the program and its longevity into the future.

Program funds to procure and operate Tennessee Vans vehicles have been provided by federal, state, and local agencies and by participants through program generated revenue. Table 3 shows the distribution of capital funds from various funding sources during 1990-2009. Approximately 9 percent of the funds have been provided by the Tennessee Department of Transportation (TDOT) in the form of 


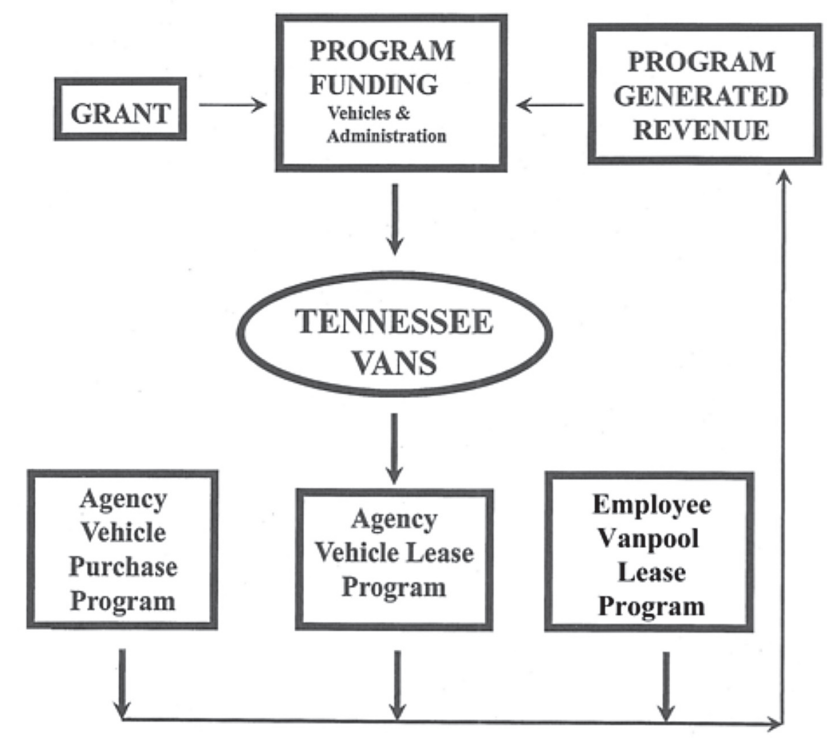

Figure 6. Tennessee Vans financial strategy.

the initial seed grant and periodic supplemental grants. Local Metropolitan Planning Organizations (MPOs) have contributed approximately 42 percent to support local van services as part of federal, state, and local congestion mitigation, air quality, and surface transportation programs. Almost half (49\%) of the funds have been received as program-generated revenue in the form of service fees received from program participants. A capital reserve fund account was established as a source of funds to purchase future vehicles. The reserve fund consists of program generated revenue and the current fund amount enables Tennessee Vans to procure up to 175 vehicles to meet future vehicle demand.

Table 3. Source of Vehicle Funds (1990-2009)

\begin{tabular}{|l|l|l|l|}
\hline Funding Source & Period & Amount & Percent \\
\hline Program Revenue & $1991-2009$ & $\$ 7,990,106$ & $48.7 \%$ \\
\hline Memphis MPO & $1993-2004$ & $\$ 4,179,807$ & $25.5 \%$ \\
\hline Knoxville MPO & $1992-2006$ & $\$ 2,595,159$ & $15.8 \%$ \\
\hline TDOT & $1990-1995$ & $\$ 1,476,157$ & $9.0 \%$ \\
\hline Nashville MPO & $1992-1993$ & $\$ 175,000$ & $1.0 \%$ \\
\hline Total Vehicle Funds & $1990-2009$ & $\$ 16,416,229$ & $100 \%$ \\
\hline
\end{tabular}


An ongoing financial objective for Tennessee Vans is to maximize the generation of revenue from program participants to cover recurring program costs. Targeted amounts of revenue are estimated for each vehicle assigned to program participants. The targeted estimates include vehicle costs, maintenance expenses, insurance fees, and fleet management expenses. Vehicle lease and purchase pricing strategies are established with the goal of recovering the estimated targeted amounts during the life of each vehicle. A comparison of the revenue generated for the vehicles that have been paid for and sold at auction with the targeted estimates of revenue for these vehicles indicates that 91 percent of the program costs were recovered. Although total cost recovery for program operations was not achieved due to financial losses from vehicle accidents, bad debt accounts, vehicle service demonstration, and pricing experiments, the overall amount of program-generated revenue is exceptionally high compared to most community public transportation program cost recovery rates.

From its inception, a major goal for Tennessee Vans is to become financially selfsufficient, that is, less dependence on government grants and more reliance on program revenue to finance future growth and operations. Substantial progress has been made in achieving this goal, as depicted in Figure 7. A comparison of the expended funds used to purchase vehicles from capital grant resources and program revenue are shown for four vehicle model year periods. During the first period (MY1990-1994), the primary source of funds to procure vehicles was from government seed grants. Program-generated revenue was not sufficient to meet vehicle demand. During the second period (MY1995-1999), both grant funds and program revenue were used to procure vehicles. The program was maturing and vehicle demand was high and producing substantial program revenue. Grant funds were used to a greater extent than program revenue during the third period (MY2000-2004). During this time period, expending remaining grant funds to procure vehicles was the primary objective. The transition from government grant support to primary dependence on program revenue for Tennessee Vans occurred during the fourth period (MY2005-2009). A major program milestone was reached in model year 2006, when the final balance of grant funds was used to procure vehicles. Since model year 2007, only program revenue has been used to procure vehicles and finance program operations. 




Figure 7. Expended funds used to purchase vehicles.

\section{Future Plans for Program Sustainability}

The discussions above summarize and highlight the major service development and implementation activities of the Tennessee Vans program during the past 20 years. Tennessee Vans has experienced a steady and sustainable rate of growth in funding and service development since its implementation in 1990. Financial resources provided during this time have enabled the program to procure 845 vehicles and to assign these vehicles as part of the vehicle lease and purchase programs to a diversity of user groups throughout the state. The lessons learned from program implementation thus far highlight the need for user participation in the design and development of program services, the importance of maintaining the role of mobility resource provider, the requirement to properly generate and manage program revenue to facilitate program sustainability, and the continuation of an evolutionary and experimental planning perspective with regard to future program growth.

Tennessee Vans is helping to fill mobility gaps through the provision of affordable vehicles. The program serves as a vehicle resource provider and assists its participants with the development and implementation of user-based service design travel options. The user-based model enables the participants to have a substantial 
degree of input and latitude with regard to providing transportation services. In essence, the service design and delivery approach adopted by Tennessee Vans is highly market driven and very viable because it works directly with its evolving market to meet their mobility needs.

The future growth of the program depends on the continued focus on identifying and addressing the occurrence of mobility gaps that occur throughout the state and to replicate the service strategies to meet these needs. This requires continuous review, documentation, and evaluation of lessons learned from program implementation. It also requires a commitment to maintain the role of a mobility resource provider and allow program participants to design and operate transportation services that directly meet mobility needs.

To assure and sustain program growth in the future, Tennessee Vans must strive to preserve and maintain financial self-sufficiency. Tennessee Vans has initiated the process of transitioning from a government-sponsored program with primary reliance on public grants as a funding source to a transportation service with primary reliance on program-generated revenue for continued operations. The program has established the capability to generate substantial revenue. Effective business practices now must be pursued to render the program operationally and financially sustainable. These practices include containing operating costs, maximizing revenue collections, and minimizing financial losses. Proper stewardship and management of program-generated funds will enable Tennessee Vans to continue to grow and develop important community mobility resources for the future.

Finally, Tennessee Vans must retain its evolutionary and experimental planning perspective. Future growth plans should include the application of program services to meet identified mobility needs in areas of the state that are underserved. Future plans should explore ways to facilitate the identification of mobility gaps and the broadening of trip purposes addressed by past, current, and new program participants. The application of alternative and appropriate service vehicles also should be explored in future plans. These vehicle options should include the incorporation of alternative "green" vehicles into the vehicle fleet to address future energy and environmental issues encountered by program participants.

In conclusion, the Tennessee Vans program provides an affordable option for program participants as they strive to overcome transportation problems that are barriers to achieving their organizational goals (e.g., employment, training, community service, etc.). The program provides essential services to meet the transportation needs of diverse user groups, including employment, job training/education, 
health care, and human services. Tennessee Vans is a user-based and financiallysustainable approach that helps to overcome the presence of mobility gaps and meet growing mobility demands in communities now and into the future.

\section{References}

Garrison, W., and J. Ward. 2000. Tomorrow's Transportation: Changing Cities, Economies, and Lives. House: Norwood, MA.

Jones, D. 2008. Mass Motorization + Mass Transit: An American History and Policy Analysis. Bloomington: Indiana University Press.

Newsom, T. 1999. A conceptual framework for the design of human mobility systems. In J. Nasar and W. Preiser, Directions in Person-Environment Research and Practice. Ashgate: Brookfield USA, Chapter 7, 153-168.

Newsom, T., and D. Meyers. 2003. An assessment of vehicle preferences and safety issues for participants in the Tennessee vans program. Center for Transportation Research, University of Tennessee. Knoxville, Tennessee.

Newsom, T., D. Meyers, and W. Gilpin. 2005. Development and selection of alternative vehicle choices for participants in the Tennessee vans program. Center for Transportation Research, University of Tennessee. Knoxville, Tennessee.

Research and Training Center on Disability in Rural Communities (RTC: Rural), The Institute of Montana Rural Institute. 2007, February. Models of rural transportation for people with disabilities. Retrieved February 11, 2009 from <http:// rtc.ruralinstitute.umt.edu/Trn/ models.htm >.

Staley, S., and A. Moore. 2009. Mobility First: A New Vision for Transportation in a Globally Competitive Twenty-First Century. Lanham, Maryland: Rowman \& Littlefield Publishers, Inc.

Urry, J. 2007. Mobilities. Malden, MA: Polity Press.

Wegmann, F. 2001. An air quality analysis for the Knoxville van transportation program. Center for Transportation Research, University of Tennessee. Knoxville, Tennessee.

Wegmann, F., and T. Newsom. 2002. Tennessee vans: Accomplishments of a statewide van transportation service delivery system - A ten year review (1990-2000). Center for Transportation Research, University of Tennessee, Knoxville, Tennessee. 
Wegmann, F., and M. Noltenius. 2008. Fifteen-passenger van safety - Recommendations on best practices for commuter and community transportation. Southeastern Transportation Center, University of Tennessee, Knoxville, Tennessee.

\section{About the Authors}

TheOdore J. Newsom, Ph.D. (tnewsom@utk.edu) is a research director at the Center for Transportation Research at the University of Tennessee (Knoxville) and is Director of the Tennessee Vans program.

DANIELLE F.MeYERS (dmeyers@utk.edu) is a senior research assistant at the Center for Transportation Research at the University of Tennessee (Knoxville). 